\title{
Students and Teachers' Perceptions into the Viability of Mobile Technology Implementation to Support Language Learning for First Year Business Students in a Middle Eastern University
}

\author{
Bilal M. Tayan \\ Graduate School of Education, Exeter University, United Kingdom \\ E-mail: bt275@exeter.ac.uk
}

Received: 09-11-2016

doi:10.7575/aiac.ijels.v.5n.2p.74
Accepted: 29-04-2017

URL: http://dx.doi.org/10.7575/aiac.ijels.v.5n.2p.74

Published: 30-04-2017

\begin{abstract}
Advancements in technology have enabled us to learn, adapt and exploit our skills and knowledge in new ways. Appreciating the potential of technology may yet give growth and enrich the process of language education, particularly through a student-centred mobile learning environment. Consequently, a constructivist approach to learning can create tremendous possibilities for both language learners and teachers. By exploiting the affordances of mobile technologies and the Internet, a new platform of learning or Mobile Assisted Language Learning (MALL) can be realised, through which learners truly learn to learn. Yet, while many of today's language institutions and places of learning have begun to understand the potential presented by mobile technology as a tool and resource to content and language development, apprehension may still exist among educational practitioners, learners and senior management. Such apprehension may stem from a lack of understanding in fully appreciating the opportunities and affordances posed by MALL in creating a support structure to learning and teaching excellence. This may be particularly true within developing countries such as those found in the Middle East. Consequently, set in a Saudi university context, the purpose of this study is to investigate learners' and teachers' perceptions towards the proposed implementation of a MALL programme, while exploring whether the promotion of mobile technologies could assist learning and become a viable support structure in teaching English as a second language. Interviews were conducted with three English instructors who teach on the first year Business English programme at the university. The study also analysed 191 student participants who completed a Likert scale questionnaire designed to explore their mobile learning experiences, attitudes and perceptions towards the proposed MALL programme in their educational context. The findings from the student questionnaire and teacher interviews generally highlight positive attitudes and a receptiveness towards mobile learning implementation. This is perhaps due to the possibility of new pedagogical scaffoldings being created through MALL in their learning/teaching environment. The results further highlighted opportunities MALL presented in facilitating communication and affording learners greater motivation to engage in independent learning, thus facilitating learner autonomy and allowing for greater collaboration within a richer learner environment. However, while analysis highlighted a proposed MALL implementation could be a useful tool to support language acquisition for ESP/ESL learners (English for Specific Purposes/English as a Second Language), technical issues, network sustainability and comprehensive training were still significant factors of concern.
\end{abstract}

Keywords: Mobile Assisted Language Learning, Perceptions, Viability, Saudi Arabia

\section{Introduction}

Mobile technologies, as an information communication platform, have increased substantially in recent years and have shown no signs of maturity or decline. This has been driven by the growth of the Internet, changes in lifestyles, work habits and social norms (Rosi Sole et al. 2010). Kukulska-Hulme and Shield (2008) have suggested that the growth of the Internet has been accelerated by the increased use of personal computers and mobile devices in the workplace and at home. In similar context, a study by McKinsey (2017) found a significant rise in mobile learning adoption around the world. The report highlighted a near three-fold increase in the mobile learning (m-learning) market, growing from $\$ 6 \mathrm{bn}$ in 2013 to over $\$ 16$ bn in 2016. Furthermore, industry reports show that mobile penetration rates in developing countries such as Saudi Arabia have grown at an exponential rate with the number of Smartphone users reaching an estimated 23 million by 2017, with sales in the Middle East and Africa projected to increase to 43 billion US dollars by the end of 2016 (Statista, 2016). Nevertheless, the growth of mobile device use has been mirrored in countries around the world, primarily because of their multiple functionalities. As there has been an upsurge in mobile communications, opportunities for educational practitioners to exploit the digital revolution is quick evolving into a debate which addresses the feasibility of using technology and mobile devices to complement and develop the language learning acquisition cycle (Crescente \& Lee, 2011; Farmer, 2008; Kidd and Keengue, 2008; 2012; Rau et al. 2008; Sharples, 2016; Tan \& So, 2016). 
Looking to the future, it may seem apparent and undeniable that technology will continue to be a significant part of our lives and may be the harbinger of the education industry, banking sector, social communication and data gathering networks (Kukulska-Hulme, 2009; Lai, 2016; Orr, 2010; Thornton and Houser, 2002; Wu and Looi, 2012). However, while technology may be ubiquitous, it should not be viewed as a substitute or a quick-fix answer to many of the challenges language learners may suffer from (Glahn, 2016; Warschauer, 2002). Rather, education and technology should co-evolve in mutually supportive roles to bridge the gap between formal and informal learning (Kukulska-Hulme, 2009; Tan \& So, 2016). Consequently, realising the significance of technology adoption in education and language learning development was identified by management a Saudi state university. The university recognised technology implementation in the teaching curriculum could perhaps create a pedagogical opportunity to accelerate language acquisition among Saudi ESP learners. Subsequently, this particular university was selected as a case-study to investigate the viability, perceptions and experiences of technology use on first year business students learning ESP. This study will also explore the extent to which technology could be used as a support mechanism for language learning and highlight the implications for m-learning adoption among ESP/ESL learners within a Saudi university context.

\section{Literature Review}

The passé of early Web 1.0 computer applications, with their mundane, static and non-interactive interface, contributed to the development and rise of Web 2.0 applications, characterised by an emphasis on a community of users collaborating and sharing in virtual environments (Kukulska-Hulme and Shield 2008). As mobile technologies evolve into more developed multi-functioning devices, language learners and teachers are offered unparalleled opportunities to access content, interact, participate, share and practice in the target language beyond the formal domain of the classroom (Glahn, 2016; Kukulska-Hulme and Shield, 2016; Soloway et al. 2001). Thus, the emergence of mobile technologies presents immense opportunities as a teaching tool and learning resource with the capability of motivating and engaging students in interactive learning out with traditional learning environments (Kukulska-Hulme and Shield, 2008; Lai, 2016). As such, their application to language pedagogy may consequently become increasingly attractive to educational practitioners.

While Rau et al. (2008) argue that the use of computers, most commonly associated with a formal and fixed place of education, did not address the changing needs of students and teachers, a realisation of the significance in mobile devices for education purposes has therefore grown. This has led many commentators to suggest the possibility of mobile devices working in tandem to existing approaches to teaching and learning in a way that provides a support structure to language education delivery through increased aspects of participation, communication and mobility in learning (Al Zahrani, 2015; Kukulska-Hulme and Shield, 2008; Sharples, Taylor and Vavolula, 2005; Uzunboylu, Cavus, and Ercag, 2009). With language learners taking on a more central role in learning both in and out of the class environment, these commentators argue that learners have realised the potential of converging the ubiquity of mobile devices to changing social norms, lifestyles and education. This may be particularly true with m-learning.

\subsection{Theories of learning}

It may be very difficult to live in a society and not be submerged by our reliance of technology with the world becoming "increasingly sophisticated, multifaceted and nuanced people need high-level learning skills to respond, learn and adjust to ever changing circumstances" (Stratham and Torell 1996: 44). For Bax (2003), he argues that with the unprecedented growth, development and adoption of technology in the global village of today, it is inevitable that technology, including mobile devices, would be merged or as Bax (2003) argues, 'normalised', into the language learning syllabi and within all learning activities. Fouts (2000) points out that it is this demand that more learnercentred environments must be realised. Appreciating this would give educational practitioners and learners alike the ability and support to solve tasks, acquire and apply knowledge and new skills by being able to connect to real world applications within a contextual framework relevant to the needs of learners. One could therefore claim that it is this requirement that has led to the developments of technology, particularly mobile platforms, being applied to learning theories.

Research has shown that learning environments which are rich in technology enhance student motivation, collaboration skills and increase student achievement (Al-Zahrani, 2015, Sarrab et al. 2016; Hwang, Wang and Lai, 2015). It is through new technologically enriched learning environments that realising the theories of learning, and how their convergence with mobile technologies to support and create scaffoldings to teaching and learning, becomes significant. As such, two well documented approaches are the Situated Learning and the Constructivist/Socio-constructivist theories.

\subsubsection{Situated learning}

First proposed by Lave and Wenger (1991), Situated learning focuses on a model whereby learning is an activity process which occurs only when placed within a specific context (Myers and Wilson, 2000). Lave and Wegner (1991) argue that learning, in any form, should not be seen as a non-representational transfer of knowledge and skills from one individual to another. Rather, learning and education evolves then occurs in a social participation process or in a learning community where the learner adopts the role of an 'active participant' in the social community (Myers and Wilson, 2000).

A study by Hung (2002) illustrates that when learning is a problem-based activity, involving decision making activities, questions and exploring case studies, individuals therefore begin to explore real-life context based situations to these problems. Here, Hung (2002) emphasises the importance of learning in a social situated context. He contends that 
when learners are involved in communities with common interests, they have an increased tendency to benefit from content and apply new knowledge, thereby facilitating memory recall and retention. Essentially, what is meant here is that when individuals are engaged in learning within a social community of shared interests, learners are compelled to reflect, learn and share on experiences and knowledge. Consequently, it could be argued that interacting in a situated environment allows students the opportunity to participate in learning by creating a catalyst to enable them to actively express their thoughts and share their ideas to make informed decisions (Cook, 2008). As such, Halverson (2009) and Omale et al. (2009) suggest that combining mobile and computer technologies to Situated learning can create a realistic educational experience for students by engaging them in real-life role plays based on a variety of real-life contexts. One could therefore claim that this then encourages students to actively interact with their environment, thereby increasing their learning experience.

Myres and Wilson (2000) sum up by noting that learning is expressed through the interactions of others within a community and when there is no interaction, no cognitive development can occur. They conclude that for learning to occur, action needs to take place. Yet, part of the action itself involves the interaction of technology to the learning cycle. Here, technology can become a part of the learning environment that stimulates knowledge and language learning (Hwang, Wang and Lai, 2015). Exploiting mobile technologies can be fostered by encouraging learners to demonstrate their understanding of language in the real world by taking photographs, images or using pictures, for example, that demonstrate body language, facial expressions and gestures that illustrate language principles in action. Applying these to mobile technologies, through camera phones, PDAs, iPads or digital cameras and sharing them in a situated online social community such as Facebook, Fotki or Flickr, can create opportunities for photo sharing, developing creative ideas or picture activities to be incorporated in the classroom. This then creates the idea of a flipped classroom, expanding the boundaries of learning within a classroom. Here, Hwang et al. (2015) contend that by engaging with the functions presented in smartphone technology, a flipped classroom is created where students can continue to learn outside of the traditional confines of the class through their active engagement and interaction in multimedia and social networking applications to collaborate with other learners in online forums, participate in research and engage in collaborative homework activities.

As the Situated theory contends that language learning, or in fact any type of cognitive development, is enhanced if it occurs in a real context, mobile devices may be significantly well suited because of their portability and their ability to draw on a variety of functions to promote learner collaboration in order to enhance the learning activity itself. Mobile devices that situate learning in authentic contexts can be evidenced by the example of Ambient Wood (Rogers et al, 2002). Previous studies conducted by Lai et al. (2007), Proctor and Burton (2003), Rodgers et al. (2010), Uzunboylu et al. (2009) and Vavoula et al. (2009), also illustrate the value of applying mobile technology to Situated learning. Thus, it appears that exploiting technology use for language education purposes can be of significant value.

However, many educational practitioners in university environments may find teaching large classes, with learners exceeding 1,000 in some cases, extremely challenging to participate in Situated learning activities. Consequently, the high number of learners in university class settings often results in having or participating in Situated learning activities, such as a visit to a museum or virtual avatar-based learning activities, perhaps impractical and unfeasible.

\subsubsection{Constructivist learning}

The Constructivist learning theory is based on the concept that people learn, understand and problem solve based on reflections from their understanding, experiences and knowledge of the world (Loyens and Gijbels, 2008). Motiwalla (2007: 583) highlights the Constructivist learning model points to the notion of the learner acting and reflecting in a particular environment, where the "action could be a task of solving a problem and reflection could be abstracting from the derived solution and accumulating in one's experimental knowledge". Motiwalla (2007) therefore argues Constructivist learning, like Situated learning, can give students more autonomy in learning. However, where the two learning theories differ is where the activity rests. In Constructivist learning, activities centre on the learner and the teacher adopts the role of observer, facilitator and motivator.

As Situated learning asserts learning can be enhanced by ensuring that it occurs in an 'authentic' context, as the location where the learning takes place impacts profoundly on the process of learning, in Constructivism, 'players', 'participants' or 'learners' construct their own knowledge. Learners do this by applying ideas, concepts and approaches based on their prior knowledge and life experiences to new constructs, regardless of their location. Here, Rau et al. (2008) suggest the best way for a learner to retain cognition and to use it later in context is to have them construct their own knowledge and experiences rather than have knowledge, to which they may not necessarily be able to relate to, constructed for them by their teacher. This reflects the growing body of research that indicates learning is an ongoing process where knowledge is best achieved when learners are able to interact and relate to certain contexts and experiences (Baek et al. 2008; Jiang and Ramsay, 2005).

For Muir-Herzig (2004), the use of information communication technologies (ICTs), including, mobile devices such as smarphones, complements Constructivist learning. Sharples (2007) point out that given technologies' relative affordances as portable and convenient devices, particular affordances in facilitating learning become evident. Here, the argument surrounds the notion that with technology use, learners become more self-aware, self-reliant and more focussed on the desire to learn. With learners merging formal and informal learning experiences by collaborating and interacting with each other more frequently through blogging or online discussion forums, interactive podcasting, hand- 
held interactive applications and games, their problem-solving and decision making skills improve in context based environments (Muir-Herzig, 2004). As the Constructivist approach focuses on students as active participants in learning, rather than as passive listeners, it could be argued that the approach facilitates social and communication skills by creating a learning environment that emphasises the integration, collaboration, exchange and sharing of ideas and knowledge. Nevertheless, the most noteworthy applications of Constructivism to mobile technologies derive from participatory simulation learning experiences (Lai et al. 2007; So, Kim and Looi, 2008). Virtual Learning Environments (VLE) such as Second Life and Languagelab.com are two such examples. Here, teachers adopt the role of 'facilitator' and learners engage in immersive activities, relevant to their interests, as part of a wider dynamic environment. Learners interact through a networked device such as an iPad or smartphone, which allows for participation in the environment they are learning about (Kukulska-Hulme and Shield, 2008). Absorbing learners into the VLE itself allows for an inevitable significant activity to take place, that is, immersed learner participation and interaction in the virtual environment which leads to enriched language acquisition (Carpenter, 2009; Liao, 2008; Lu, 2008; Taylor; 2009). Students not only become involved in the matrix, they become the matrix and become witness to how their actions affect their environment as a whole.

\subsection{MALL studies in a Middle Eastern context}

However, in the Middle East, few studies have been conducted which analyse the benefits and synthesise the results of previous empirical studies on m-learning overtime (Al Zahrani, 2015; Marinakou and Giousmpasoglou, 2014). While Middle Eastern countries have the potential to fund policy initiatives and strategies to implement ICT programmes in language education, little has been done. Consequently, focusing on an area that has had relatively little research conducted demonstrates the importance and significance of this study.

Yet, one of the early studies conducted in the Middle East was by Mustafa (2001) who highlighted the significant role of ICTs in language education for students at a Jordanian university. The study analysed the extent to which ICTs could enhance the pronunciation and oral skills of students enrolled in an ESP course. Mustafa (2001) concluded that technology use is significantly important in developing oral and pronunciation skills. Again, what can be deduced is the significance of technology to language learning. Embracing technology and exploiting it can have positive effects on effective language acquisition and greatly assist in creating a support structure for language educators.

In another study, Almekhlafi (2006) examined two groups of primary school students to explore the effects of technology use on students' overall performance in English language learning. One group studied in the English language using textbooks, while the other group studied the same curriculum but were taught using computer and mobile-assisted learning. By the end of the English course, the researcher found that language learners engaging in technology based activities out-performed the first group who did not engage in technology use in the classroom. Almekhalfi's (2006) explanation of this showed that technology adoption motivated learners to excel in language learning. This point is also supported by Warchauser (1996). Subsequently, it could further be inferred that technology can act as a support structure to language learning by facilitating intrinsic desires to learn amongst students.

A similar study was conducted by Al-Fahad (2009) at a university in central Saudi Arabia which explored university students' perceptions towards technology and how technology use among teachers and students could improve student retention rates. The study indicated mobile technology integration in classrooms would become positively welcomed among learners. Al-Fahad's (2009) study concluded by arguing there would be an inevitable integration of technologies in tertiary education institutions in Saudi Arabia (Almekhalfi, 2006; Baek et al., 2008; Kukulska-Hulme and Shield, 2008; Jiang and Ramsay, 2005). However, this may be an important point to criticise especially when Internet and telecommunications infrastructure in Saudi Arabia is not only limited to major cities and large towns, but also because of the erratic internet connections that are marred by restricted bandwidth and downloading capabilities among the general population.

Subsequently, a study conducted by Shuler, Winters and West (2013: 30), drew a conclusion that mobile learning is still in its infancy. The researchers pointed out that m-learning and its implementation in the field of education is still at a premature stage, as "most mobile learning projects to date have been experimental in nature, focusing on exploring how mobile technologies can support new and innovative teaching and learning practices" while arguing that current research in $\mathrm{m}-\mathrm{learning}$ "are usually short-term, small-scale pilot projects, which lack the capacity to reach large numbers of learners over long period of time". Though other studies focusing on the Middle Eastern University context, for example Sarrab et al. (2016) and Al Zahrani (2015), have attempted to address this issue, the few projects that have been conducted in the Middle Eastern context are nevertheless useful as a basis of understanding and supplement the growing body of discussion. Analysis relating to student and teacher perceptions and attitudes towards m-learning in language education are significant to understanding whether or not users and educational practitioners will accept and adopt technology and whether m-learning can be a viable and sustainable tool and resource in language education in a Saudi context. However, there are several issues that still need to be addressed and investigated comprehensively. Thus the next section explores these points further and discusses whether tutor and tutee language education experiences are indeed positively influenced by m-learning.

\section{Context of the Study}

In late 2014, managers and senior lecturers at a state university in the Western Region of Saudi Arabia were reviewing ways to improve the language competence of first year Business Administration students enrolled in a Business English 
intermediate course. They believed that by introducing ICTs, specifically mobile devices into the learning environment, significant improvements in language acquisition would become apparent.

The importance in creating a support mechanism that would result in increased exposure to the target language was identified as a significant factor that would develop the linguistic competence of students. Implementing mobile technologies was seen as a way in creating this support mechanism. Therefore, mobile technologies or Mobile Assisted Language Learning (MALL) or m-learning became an attractive way forward. M-learning was seen by university management as potentially providing pertinent benefits in facilitating the teaching and learning experience for ESP learners and educational practitioners in the university. As students and teachers are able to readily access learning content whenever and wherever required, users would therefore have access to language learning contact regardless of geographic or time restrictions. As such, students would have greater exposure and interaction with the target language, while teachers would have the simplification of preparing teaching materials and administering tasks. Due to these affordances, amongst others previously highlighted, management at the university provisionally decided to implement a MALL programme by the end of the 2016-2017 academic year. Consequently, the hypothesis of this study contends that if both students and teachers realise the affordances and potential of mobile technologies to teaching and learning within their context, then MALL adoption can become a significant and viable support structure in language education within a Saudi higher education context.

\subsection{Objectives}

The purpose of this study is to explore learners' and teachers' perceptions on the viability of a proposed implementation of a MALL programme and explore whether the promotion of mobile technologies can support learning and be a viable pillar for teaching English for Specific Purposes (ESP) in a Saudi university context. In this research, a specific environment is chosen, namely ESP instruction in a Saudi university. Analysis will also include a discussion on the extent to which mobile technologies could create a ubiquitous learning and teaching environment.

Thus, the aim of this research study is to investigate the attitudes, perceptions, experiences and viability of a MALL programme in a Saudi university classroom and explore whether its introduction can be a supporting pillar to facilitate first year business students in English language education.

\subsection{Research Questions}

Through the use of teacher interviews and student questionnaires, the study seeks to address the following questions:

1. Would user mobile device functionalities and their use in the classroom impede on m-learning activities?

2. What are student and teacher attitudes and perceptions towards mobile learning implementation?

3. Would implementing smartphones in a Saudi university classroom be a viable support structure to language education?

4. What impacts and challenges are evident when applying m-learning in the Saudi context?

Using teachers and students who were presented with opportunities by university management to engage in m-learning activities, the study hoped to gain greater insights from the research participants on their thoughts, reflections, attitudes and perceptions of mobile device/smartphone adoption to facilitate and support the current classroom approach to English language learning in their context. By exploring teachers' and students' perceptions towards m-learning adoption, realising the affordances, opportunities and challenges that become apparent with smartphone and Internet use, can possibly enable educators to positively enhance students' learning experience. In order to accomplish this, ESP teachers and students were included in the study.

\subsection{Research method}

In enabling the study to comprehensively address the research questions, adopting the rigour of a mixed methods approach can significantly improve the validity of the research instruments employed in the research (Creswell and Plano Clark, 2011). Subsequently, in addressing the research questions, primary data collection involved a mixed methods research approach that involved qualitative one-to-one interviews with three ESP instructors who teach on the first year Business English programme at the Saudi university. ESP student and teacher participants from the Business Administration College of a Saudi university were purposefully chosen as they were the only relevant sample the researcher had access to in order to conduct the study. Three university language instructors were interviewed in a private office. Interviews lasted approximately 10 minutes and were digitally recorded using a smartphone. Following Brown's (2001) arguments in which questionnaire use in research is an effective and efficient approach to gathering information on participant attitudes and perceptions on subject matters, a closed-ended Likert scale questionnaire was employed with student participants. The research was thus complimented quantitatively with the same interview questions asked through the distribution of 200 closed-ended online student questionnaires. The questions posed in both the teacher interviews and student questionnaires were designed to explore mobile learning experiences, attitudes and perceptions towards a proposed MALL programme in their educational context. The online questionnaire was made available at http://bit.ly/1aKEE0Y using Kwiksurveys. Students were given two weeks to complete the questionnaire and the researcher reminded students to complete the questionnaire at the end of their ESP class. All participants were informed on their basic right to data protection, confidentiality and anonymity through a consent form. 


\section{Results}

In order to later establish whether mobile device functionality and mobile device adoption would impede on m-learning activities and access to online content, the first section of inquiries posed in the student questionnaire analysed users' ability to access the Internet, their confidence in doing so and the frequency to which they accessed the Internet and whether language education software was already installed on their device.

The findings from the 191 returned student questionnaires highlighted $65 \%$ of respondents strongly agreed they regularly use a mobile device throughout the day during their time at university. This figure is in similar comparison to $60 \%$ of respondents who strongly acknowledged they had regular access to a mobile device with Internet access and with $62 \%$ accessing the Internet on their mobile device at least once a day. As such, nearly three quarters (71\%) of respondents also strongly felt that they were very confident in accessing the Internet using a mobile device with $62 \%$ accessing the Internet on their mobile device at least once a day. The relatively high rate of mobile device use and Internet access can be seen in similarity to the number of respondents $(86 \%)$ who confirmed they had downloaded language education software on their mobile device and were experienced in using the functions on their mobile device for language education purposes. Nearly $40 \%$ of students strongly agreed and $46 \%$ agreed they used their device or applications for language education purposes. A similar total (51\% strongly agreeing and 34\% agreeing) was also evident when students stated they would be comfortable using a mobile device in class for language education purposes. In response to Research question 1, this would seem to suggest that mobile device functionalities and their use in the classroom could create scaffoldings for language education development and encourage m-learning activities, due to user confidence and existing experience in using their devices for language learning purposes.

In addressing Research question 2, the student questionnaires and teacher interviews also explored student and teacher attitudes and perceptions to mobile learning. More than half of the respondents (51\%) strongly agreed and 34\% agreed that they would be comfortable using a mobile device in class. A combination of both these results illustrated that $85 \%$ of respondents would be comfortable using mobile devices in the classroom for language education purposes. This is probably because many respondents previously acknowledged they had a mobile device with Internet access and were confident in using it for language education purposes. Consequently, in relation to Research question 3, support for implementing mobile technologies in the classroom is seen as positive. This is reinforced by the general attitudes the students and teachers had towards mobile learning. Here, $84 \%$ of students questioned and $100 \%$ of teachers interviewed, favoured m-learning as an effective way to support language education. This can be seen in marked contrast to the $16 \%$ of students who felt that m-learning was not an effective and efficient way to support their language education. This may be because the respondents purposefully selected perhaps had no experience in using a mobile device for language education, where $15 \%$ of respondents acknowledged this point and as such, $14 \%$ responded by saying they would not recommend m-learning to other students, teachers or to the university board. This is perhaps due to the $46 \%$ of student respondents who pointed out that using a mobile device would discourage class collaboration and interaction with other students. As such $30 \%$ of respondents (13\% of whom strongly agreed) stated that mobile device use in the classroom would be very difficult and inappropriate and $29 \%$ of student respondents pointed out (16\% strongly agreeing) that they preferred working in a classroom environment that did not implement the use of mobile devices to the teaching syllabus. However, $87 \%$ of student respondents and $100 \%$ of teachers would recommend $\mathrm{m}-$ learning to others. Teacher interview responses highlighted the superior nature and ability of mobile devices to access, manage and share data regardless of time and space limitations (Orr, 2010), the affordances presented by device portability to support improved learning processes through student collaboration and developed communication levels (Liang et al. 2005). Teacher responses highlighted the opportunities to improve English language learning with the ubiquitous nature of user interactions through mobile devices functions and use (Lai et al. 2007; Tan and So, 2015). In context, $85 \%$ of student respondents (48\% strongly agreeing) and 100\% of teachers pointed out they would favour the implementation of m-learning in the classroom. On the other hand, the acceptance of mobile technology use for language education purposes among most student respondents rises to $92 \%$ if the university board implements it in the ESP curriculum.

From what can be seen from the teacher and student responses are a generally positive attitude to m-learning adoption in the classroom. This pattern is continued when teacher and student respondents were asked about their thoughts on the viability of mobile technologies being a support mechanism to language education in their context. Of the 191 questionnaires returned, $70 \%$ of student responses and $100 \%$ of teacher responses highlighted m-learning can bring positive influences to language learning.

However, in response to Research question 4, an examination of the student and teacher responses in relation to the technical facilities at the university indicate that current communications infrastructure is not sufficient to viably implement an effective m-learning policy in the classroom. From the student questionnaire responses, 80\% $39 \%$ strongly agreeing) and $100 \%$ of teachers felt that mobile device use in the classroom could be restricted by the lack of charging facilities. Also, teachers and students are aware of the relatively weak telecommunications infrastructure in the country, $89 \%$ of students agree (of whom $68 \%$ strongly agreed) that the university is not ready to implement mlearning activities in the classroom because of the recurrent Internet communication failures. This view was also supported by $100 \%$ of the teachers interviewed. 
In summary, the primary data obtained from both the student questionnaires and teacher interviews indicated positive attitudes and a willingness to adopt mobile device use in the classroom to support English language learning. The positive attitudes and perceptions in using mobile devices for learning purposes were evident in both teachers and students. Confidence in mobile device adoption related to benefits in increased learner motivation, increased learner autonomy, improved collaboration in learning as well as the opportunity in increasing the frequency of communication and interactions with the teacher and other learners. Moreover, while analysis highlighted a proposed MALL implementation may be a useful tool to support language acquisition for ESP learners, the fundamental issue of its suitability for non-technical minded instructors, teacher and student training programmes in using the software and the relative dependence MALL may have on network technologies still needs to be clarified.

\section{Discussion}

Theory from the literature review and primary data from the results section all highlight a common trend. This trend highlights a significant issue. Though mobile technologies pose several affordances to learners and teachers in language education, there may be several challenges to their adoption and implementation. This may be particularly true for countries with unreliable communication/Internet infrastructure, including Saudi Arabia and many other countries in the Middle East and North Africa. It can thus be illustrated that being aware, understanding and accepting the immense transition required for successful m-learning implementation in pedagogy to be established, is paramount. The drawbacks posed by mobile technologies may indeed influence resistance and negative attitudes towards $\mathrm{m}$ learning implementation and use, either in or out of the classroom. Reflecting back on Research question $1 \& 2$, the study confirmed that both student and teacher participants would be comfortable using mobile devices in the classroom for language education purposes, believing that m-learning was an effective and efficient way for learning and teaching. These responses related to the ability of mobile technologies in improving levels of communication and increased motivation to engage students in interactive and enriching learning practices. By accepting the harmonisation of mlearning in the classroom, it seems that teachers and students are receptive to technology use to aid language acquisition. However, there was evidence of a significant difference between participants who had positive attitudes towards mobile device use in the classroom to facilitate language instruction and those who had negative ones. Here, it may perhaps be appropriate to assume student participants who (i) do not have access to a mobile devices with Internet capabilities (5\%), (ii) have little or no experience using mobile devices for language education purposes $(15 \%)$ and (iii) have little or no awareness in the concept of m-learning $(8 \%)$, contributed to the difference in attitudes.

With regards to responses on the effectiveness of $\mathrm{m}$-technologies in supporting language education, teacher participants also responded very positively. Geddes (2004) claims that while learning can be done anywhere and at any time mlearning can strongly improve positive communication between students and learners. Consequently, $100 \%$ of teacher responses and $94 \%$ (60\% strongly agreeing) of student responses supported Levy (2005) as well as Kukulska-Hulme and Shield (2008) in that m-learning can assist in enabling quicker feedback from teachers. This can be seen in marked comparison to $7 \%$ of student responses who did not agree m-learning could facilitate quicker feedback from teachers. This demonstrates that student and teacher participants not only commonly favour the implementation and use of mobile devices for language education purposes, but it deduces one to conclude that introducing mobile learning activities in the classroom can create new pedagogical scaffoldings (thus further addressing Research question 3). As the literature review illustrates, that by incorporating mobile technologies in the classroom, positive interactions may result. This point is supported by Almekhlafi (2006), Kulkuska-Hulme, (2009), Kukulska-Hulme and Shield (2016), Rau et al. (2008) and Traxler (2009). In support of this conclusion, Robertson et al. (1987), for example, note that students who joined technology enriched language learning programmes show significantly higher levels of self-esteem and motivation to learn. Warchasuer (2004) further points out technology use in the education sector acts as a positive stimulus, a motivator and as a catalyst for learners to learn more effectively.

Therefore, what evolves from technology use is the intangible benefit of increased motivation to learn. This is point is also supported by findings of this study which highlight that $85 \%$ of student participants and $100 \%$ of teacher participants felt technology can be a motivational stimulus to the learning cycle and inevitably, to students learning a second or foreign language. What can be deduced is that when mobile devices are applied to learning activities, they can work as a mechanism to increase learners' extrinsic levels of motivation to participate in learning activities which would subsequently create positive learning outcomes or goals.

This study was an attempt to investigate learners' and teachers' perceptions towards the proposed implementation of a MALL programme in a Saudi state university, and exploring whether the promotion of mobile technologies could assist learning and teaching. This would allow for greater analysis into whether mobile technology use in pedagogy could work as a viable support structure in teaching English for Specific Purposes (ESP), or indeed for language education in general, within a Saudi higher education context.

\section{Conclusion}

The study has not only added depth to the limited but growing body of knowledge into m-learning viability in a Saudi university context, but has also provided evidence to suggest teachers' and students' willingness to adopt new platforms to improve English language teaching and learning in their context. Despite the tangible and intangible challenges facing m-learning, the motivation of students and the eagerness of their teachers to employ mobile technologies to 
support classroom instruction can create a beacon of opportunities in developing and allowing learning to continue beyond the confines of the classroom.

Moving forward, with their rapid proliferation witnessed worldwide, social media encourage individuals to form communities and facilitate communication. Perhaps one noteworthy limitation of this study was its inability to investigate the role of social media, including Facebook or Edmodo, an educational micro-blogging social network platform, in facilitating learner collaboration, knowledge sharing, learner support and motivation to write and engage in collaborative, yet interactive, learning activities in real-life contexts. Though the study does provide an impetus to engage in m-learning, the issues of curriculum design and the effective implementation of an m-learning strategy to truly engage and motivate students to participate in meaningful learning when interacting with their environment are still areas that require investigation and development.

Research published on m-learning in the Middle Eastern context has illustrated m-learning implementation is not only at its infancy, but analysis to date has not comprehensively shown m-learning is indicative to continually facilitating effective teaching and learning practices online. Therefore, longitudinal research is required, not only on the same sample groups over a significant period, but research which also explores the multiple functions of the technology itself to investigate the core issues in whether m-learning does improve students' cognitive abilities in language learning and to what extent. Considering the context in which MALL is implemented is fundamental (Buckenmayer, 2011), exploiting technology, particularly mobile device technology, can result in the potential for innovative possibilities to flourish, revolutionary new opportunities to develop and modern pedagogical scaffoldings in teaching and learning to advance. These new scaffoldings would enable language learning to be conducted regardless of time or geographical restrictions, while improving learner motivation and developing a more learner-centred environment. This could be achieved with the use of collaborative online activities such as wikis, blogs or mobile web based communication applications such as WhatsApp to support writing skills or perhaps adopting Edmodo, could be applied to support social collaboration and communication for teaching and learning purposes. For the learner, experiencing a personal interaction with mobile devices in a constructivist-based environment can bring improved levels of motivation, personalised engagement, collaboration and autonomy in learning relative to the learner's interests.

Capitalising on the universal availability, ease of use and the intrinsic benefits that may come hand-in-hand with mobile technologies, may make m-learning a viable, exciting and interesting choice for language educators and learners. The findings of this study can therefore be regarded as significant in illustrating that mobile technology can create new positive learning experiences and affordances beyond traditional classroom education by providing learners greater opportunities to engage and interact in a common community of practice. The findings from the student questionnaires and teacher interviews highlighted the generally positive experiences, attitudes and perceptions towards mobile learning. However, it is not to assume that having learners participate in online communities, for example, automatically assures superior language proficiency (Norton, 2000). Rather, mobile technology, and the benefits that follow suit, should be seen as a gateway to increased opportunities to develop the autonomy of learning in oneself.

\section{References}

Al-Fahad, F. (2009). Students' attitudes and perceptions towards effectiveness of mobile learning in King Saud University, Saudi Arabia. The Turkish Online Journal of Educational Technology. 8(2), 111-119.

Almekhlafi, A. (2006). The effect of Computer Assisted Language Learning (CALL) on United Arab English as a Foreign Language (EFL) School Students' Achievements and Attitude. Journal of Interactive Learning Research, $17(2), 121-142$.

Al-Zahrani, A. (2015). The Impact of Flipped Classroom on Cognitive Achievement in eLearning Course among Students from the Faculty of Education at King Abdulaziz University [Arabic]. The Journal of the Faculty of Education at the University of Al-Azhar, 162(1).

Baek, Y., Jung, J. \& Kim, B. (2008). What makes teachers use technology in the classroom? Exploring the factors affecting facilitation of technology with a Korean sample. Computers and Education, 5(1), 224-234.

Bax. S. (2003). CALL- past, present and future. System, 31(1), 13-28.

Brown, J. (2001), Using Surveys in Language Programs. Cambridge: Cambridge University Press.

Buckenmayer, J. (2011). Revisiting teacher adoption of technology: Research implications and recommendations for successful technology integration. College Teaching Methods and Styles Journal, 4(6), 7-10.

Carpenter, B. S. (2009). Virtual worlds as educational experience: Living and learning in interesting times. Journal of Virtual Worlds Research, 2(1), 1-4.

Cook, V. (2008). Second Language Learning and Language Teaching. London: Hodder Press.

Creswell, J. W. \& Plano Clark, V. L. (2011). Designing and Conducting Mixed Methods Research. Thousand Oaks: Sage Publications.

Farmer, L. (2008). Learning on the Move: Making Technology Appealing to Girls. CSLA Journal, 32(1), 19-21. 
Fouts, J. (2000). Research on computers and education: Past, present and future. Seattle: Seattle Pacific University.

Geddes, S. J. (2004). Mobile learning in the $21^{\text {st }}$ century: Benefits to learners (online), Knowledge Tree e-journal, 30(3), 214-228. Retrieved on 16/09/2016 from

http://knowledgetree.flexiblelearning.net.au/edition06/download/geddes.pdf

Halverson, R. (2009). Rethinking Education in the Age of Technology. London: Teachers College Press.

Hung, D. (2002). Situated cognition and problem-based learning: Implications for learning and instruction with technology. Journal of Interactive Learning Research, 13(4), 393-415.

Hwang, G., Wang, S., \& Lai, C. L. (2015). Seamless flipped learning- a mobile technology-enhanced flipped classroom with effective learning strategies. Journal of Computers in Education, 2(4), 449-473.

Jiang, W., \& Ramsay, G. (2005). Rapport-building through CALL in teaching Chinese as a foreign language: An exploratory study. Language Learning \& Technology, 9 (2), 47-63.

Kukulska-Hulme, A. \& Shield, L. (2008). An overview of mobile assisted language learning: From content delivery to supported collaboration and interaction. ReCALL, 20(3), 271-289.

Kukulska-Hulme, A. (2009). Will mobile learning change language learning, ReCALL, 21(2), 157-165.

Kukulska-Hulme and Shield, A., \& Sharples, M. (2016). Waypoints along learning journeys in a mobile world. In W. Ng \& T.M. Cummings (Eds), Sustaining mobile learning: theory, research and practice (pp. 43-56). New York: Routledge.

Kidd T. \& Keengwe J. (eds.) (2010), Adult Learning in the Digital Age, Hershey: Information Science Reference.

Koszalka, T. A. \& Ntloedibe-Kuswani, G. (2010). Literature on the safe and disruptive learning potential of mobile technologies. Distance Education, 31(2), 139-157.

Lai, C., Yang, J., Chen, F., Ho, C., \& Chan, T. (2007). Affordances of mobile technologies for experimental learning: The interplay of technology and pedagogical practices. Journal of Computer Assisted Learning, 23(4), 326-337.

Lave, J. \& Wenger, E. (1991). Situated Learning: Legitimate Peripheral Participation. Cambridge: Cambridge University Press.

Levy, M. (2005). Why Call CALL 'CALL’? Computer Assisted Language Learning, 18(3), 143-149.

Liao, C. L. (2008). Avatars, second life, and new media art: The challenge of contemporary art education. Art Education, 61(2), 87-91.

Looi, C., Wong, L., So, H., Seow, P., Toh, Y., Chen, W., Zhang, B., Norris, C. \& Soloway E. (2009). Anatomy of a mobilised lesson: Learning my way. Computers and Education, 53(4), 1120-1132.

Loyens, M., \& Gijbels, D. (2008). Understanding the effects of constructivist learning environments: introducing a multi-directional approach. Instructional Science, 36, 351-357.

Lu, L. R (2008). Art cafe: A 3d virtual learning environment for art education. Art Education, 61(6), 48-53.

Lugo, M. T. and Schurmann, S. 2012. Turning on Mobile Learning in Latin America: Illustrative Initiatives and Policy Implications (online). Paris, UNESCO. Retrieved on 16/09/2016 from http://unesdoc.unesco.org/images/0021/002160/216080E.pdf

Marinakou, E. and Giousmpasoglou, C. (2014). M-Learning in higher education in Bahrain: The educators' view. Paper for the $6^{\text {th }}$ e-learning Excellence in the Middle East Conference - Leadership, Design and Technology for the $21^{\text {st }}$ Centure Learning, Dubai, 3-5 March.

McKinsey \& Company. (2017). Transforming learning through mEducation. Accessed on 08/11/2017 from: http://www.mckinsey.com/ /media/mckinsey/industries/social\%20sector/our\%20insights/transforming\%20learning\%2 0through $\% 20$ meducation/transforming-learning-through-meducation-final.ashx

Motiwalla, L. (2007). Mobile Learning: A framework and evaluation. Computers and Education, 49(3), 581-596.

Muir-Herzig, R. (2004). Technology and its impact in the classroom. Computers and Education, 24(2), 97-104.

Mustafa, Z. (2001). Non-courseware factors involved in using multimedia in foreign language instruction, Grazer Linguistiche Studien, 55(1), 39-50.

MyEnglishLab (2016). MyEnglishLab, Pearson (online). Retrieved on 16/06/2016 from http://www.myenglishlab.com

Myers, K. M., \& Wilson, B. G. (2000). Situated Cognition in Theoretical and Practical Context. In D. Jonassen, \& S. M. Land, Theoretical Foundations of Learning Environments (pp. 57-88). New Jersey: Lawrence Erlbaum Associates.

Norton, B. (2000), Identity and language learning. Gender, ethnicity and educational change. London: Pearson.

Omale, N., Hung, W., Luetkehans, L. \& Cooke-Plagwitz, J. (2009). Learning in 3-D multiuser virtual environments: Exploring the use of unique 3-D attributes for online problem based learning, British Journal of Educational Technology, 40(3), 480-495.

Orr, G. (2010). A Review of Literature in Mobile Learning: Affordances and Constraints. Proceedings of the $6^{\text {th }}$ IEEE International Conference on Wireless, Mobile and Ubiquitous Technologies in Education (WMUTE), 107-111. IEEE. 
Proctor, N., \& Burton, J. (2003) Tate modern multimedia tour pilots 2002-2003, In J. Attewell, G. Da Bormida, M. Sharples, \& C. Savill-Smith (Eds.) M Learn 2003: Learning with mobile devices (p. 54-55) London: Learning and Skills Development Agency.

Rau, P., Gao, Q., \& Wu, L. (2008). Using mobile communication technology in high school education: Motivation, pressure and learning performance. Computers and Education. 50(1), 1-22.

Rogers, Y., Scaife, M., Harris, E., Phelps, T., Price, S., Smith, H., Muller, H., Randal, C., Moss, A., Taylor, I., Stanton, D., O'Malley, C., Corke, G., \& Gabriella, S. (2002). Learning through digitally-augmented physical experiences: Reflections on the Ambient Wood project (online). Retrieved on 29/09/2016 from

http://citeseerx.ist.psu.edu/viewdoc/download?doi=10.1.1.103.9373\&rep=rep1\&type=pdf

Robertson, E. B., Ladewig, B. H., Strickland, M. P., \& Boschung, M. D. (1987). Enhancement of self-esteem through the use of computer-assisted instruction. Journal of Educational Research, 80(5), 314-316.

Rogers, Y., Connelly, K., Hazelwood, W. and Tedesco, L. (2010). Enhancing learning: A study of how mobile devices can facilitate sense making. Personal and Ubiquitous Computing, 14(2), 111-124.

Rosi Solè, C., Calic, J. \& Neijman, D. (2010). A social and self-reflective approach to MALL. ReCall, 22(1), 39-52.

Sarrab, M., Al Shibli, I. \& Badursha, N. (2016). An Empirical Study of Factors Driving the Adoption of Mobile Learning in Omani Higher Education. International Review of Research in Open and Distributed Learning, 17 (4), 331-349.

Sharples, M. (2007). Introduction to Special Issue of JCAL on mobile e-learning, Journal of Computer Assisted Learning. 23(4), 283-284.

Sharples, M., Taylor, J., \& Vavoula, G. (2005). Towards a theory of mobile learning. University of Birmingham, UK. Retrieved from

http://citeseerx.ist.psu.edu/viewdoc/download?doi=10.1.1.523.4590\&rep=rep1\&type=pdf

Shuler, C., Winters, N., \& West, M. (2013). The Future of Mobile Learning: Implications for Policy Makers and Planners. Paris: UNESCO.

So, H., Kim, I \& Looi, C. (2008). Seamless Mobile learning: Possibilities and Challenges Arising from the Singapore Experience. Educational Technology International. 9 (2), 97-121.

Statista (2016). Smart phone users in Saudi Arabia (online). Retrieved on 07/11/2016 from https://www.statista.com/statistics/494616/smartphone-users-in-saudi-arabia/

Stevenson, J., and Gross, S. (1991). Use of a Computerized Adaptive Testing Model for ESOL/Bilingual Entry/Exit Decision Making. Computer Assisted Language Learning and Testing, 223-235.

Stratham, D. S., \& Torell, C. R. (1996). Computers in the classroom: The impact of technology on student learning. Indiana: Army Research Institute.

Soloway,E., Norris, C., Blumenfeld, P., Fishman, B., Krajcik, J., \& Marx,R. (2001) Logon education: handheld devices are ready at hand, Communications of the ACM, 44(6), 15-20.

Tan, E. \& So, H. (2015). Rethinking the Impact of Activity Design on a Mobile Learning Trail: The Missing Dimension of the Physical Affordances. IEEE Learning Technology, 8(1), 98-100.

Taylor, R. (1980). Computer in the school: Tutor, tool, tutee. London: Teachers College Press.

Taylor, P. G. (2009). Can we move beyond visual metaphors? Virtual world provocations and second life. Journal of Virtual Worlds Research, 2(1), 4-7.

Thornton, P. \& Houser, C. (2002). M-Learning in transit. In P. Lewis (Ed.), The changing face of CALL (p. 229-243). Lisse: Swets and Zeitlinger.

Traxler, J. (2009). Learning in a Mobile Age. International Journal of Mobile and Blended Learning, 1(1), 1-12.

Uzunboylu, H., Cavus, N. \& Ercag, E. (2009). Using mobile learning to increase environmental awareness. Computers and Education, 52(2), 381-389.

Vavoula, G., Pachler, N. \& Kukulska-Hulme and Shield A. (2009). Researching mobile learning: Framework, tools and research designs. Oxford: Peter Lang Publishing.

Warschauer, M. (2002). A developmental perspective on technology in language education. TESOL Quarterly, 36(3), 453475 .

Warschauer, M. (2004). Technological change and the future of CALL. In S. Fotos \& C. Brown (Eds.), New Perspectives on CALL for Second and Foreign Language Classrooms (pp. 15-25). New Jersey: Lawrence Erlbaum Associates.

Wu, L. \& Looi, C-K. (2012). Agent prompts: Scaffolding for productive reflection in an intelligent learning environment. Journal of Educational Technology \& Society, 15(1), 339-353. 